Article

\title{
Measuring the Generosity of Parental Leave Policies
}

\author{
Adeline Otto *, Alzbeta Bártová and Wim Van Lancker \\ Centre for Sociological Research, KU Leuven, 3000 Leuven, Belgium; E-Mails: adeline.otto@kuleuven.be (A.O.), \\ alzbeta.bartova@kuleuven.be (A.B.),wim.vanlancker@kuleuven.be (W.V.L.) \\ * Corresponding author
}

Submitted: 21 December 2020 | Accepted: 11 May 2021 | Published: 11 June 2021

\begin{abstract}
In order to investigate and compare welfare states or specific welfare programmes, scientists, opinion-makers and politicians rely on indicators. As many of the concepts or objects studied are somewhat abstract, these indicators can often only be approximations. In comparative welfare-state research, scholars have suggested several approximating indicators to quantitatively measure and compare the generosity of public welfare provision, with a special focus on cash benefits. These indicators include social spending, social rights and benefit receipt. We present these indicators systematically, and critically discuss how suitable they are for comparing the generosity of parenting leave policies in developed welfare states. Subsequently, we illustrate how the operationalisation of leave generosity by means of different indicators can lead to different rankings, interpretations and qualifications of countries. Hence, indicator choices have to be considered carefully and suitably justified, depending on the actual research interest.
\end{abstract}

\section{Keywords}

administrative data; benefit generosity; inclusiveness; leave policies; parental leave; social policy indicators; social rights; survey data

\section{Issue}

This article is part of the issue "The Inclusiveness of Social Rights: The Case of Parental Leave Policies" edited by Sonja Blum (University of Hagen, Germany) and Ivana Dobrotić (University of Oxford, UK / University of Zagreb, Croatia).

(C) 2021 by the authors; licensee Cogitatio (Lisbon, Portugal). This article is licensed under a Creative Commons Attribution 4.0 International License (CC BY).

\section{Introduction}

Leave policies for parents have not only emerged as an important subject in scientific research, but also increasingly feature in public debates. With the ambition to achieve more-equal access to employment-related social rights and to reconcile paid work and family responsibilities, parental leave in particular has been the subject of various policy reforms, both within and outside Europe. Together with maternity and paternity leave, these policies vary substantially across countries (Koslowski, Blum, Dobrotić, Kaufman, \& Moss, 2020) but also share some common trends (Moss \& Deven, 2019).

To be able to compare public welfare policies across space and time, and to inform policy-making, scholars have sought to develop adequate indicators. 'Generosity' can be considered a key concept behind most of these indicators. In comparative public policy research, the concept is frequently used when comparing the budgetary volume of social programmes (e.g., Castles, 2002, 2009) or policy aspects such as the size of the population covered for a particular social risk by a specific public programme, the eligibility conditions of programmes, the duration of benefit payments and the amount of cash benefits (e.g., Kangas \& Palme, 2007; Nelson et al., 2020; Scruggs, 2007). The first comparative social policy indicators focused on policies that protect against 'old social risks' (e.g., unemployment or illness). With emerging 'new social risks' (Bonoli, 2005) and policies such as parenting leave, a need for comparative quantitative indicators that can summarise the characteristics of these policies developed. In constructing these new indicators, researchers tended to build on the generosity concept as applied in the comparative study of policies such as unemployment protection programmes. When doing so, some researchers refer to benefit generosity exclusively 
in terms of benefit amounts (e.g., Dobrotić \& Blum, 2019; Ranci, Österle, Arlotti, \& Parma, 2019) and others refer to it also in terms of the coverage rate and eligibility criteria of a benefit, and/or the duration for which it is granted (e.g., Nelson et al., 2020; Ray, Gornick, \& Schmitt, 2010). However, this does not take into account the multidimensionality of parenting leave policies. The role of the 'new social risk' policies-and parental leave in particular-is not only to protect against income loss by generous benefits, but also to prevent the adverse effect of becoming a parent on women's position on the labour market and consequently on gender equality.

The multidimensionality of leave policies challenges the suitability of the generosity concept. Further there is not yet a strong consensus among researchers about the actual meaning of 'generosity' in the context of parenting leave policies. For example, generous cash benefits may be beneficial in the short term, but if they are paid over an extended period of time, they may actually hinder women's career progress and, in the long term, exacerbate gender income inequality and the risk of poverty (Bruning \& Plantenga, 1999; Pronzato, 2009). Some scholars have tried to address this ambiguity in the generosity concept and have produced a comparative indicator that combines the duration of benefit payment with the level of benefit. This 'full-time equivalent' of leave indicates how long a leave would be paid if it was to compensate for 100 percent of foregone earnings (Ray et al., 2010; Thévenon, 2011). However, gender equality has been recognised as a dimension of leave policies that is distinct from generosity. For example, Ray et al. (2010) created a gender equality index based on the proportion of leave reserved for fathers and the benefit level. More recently, Dobrotić and Blum (2020) have challenged the 'generosity' concept by focusing on the access to leave benefits. This aspect has been largely overlooked in leave research literature which mostly compares the generosity of leave policies on the basis of leave duration, replacement rates (i.e., the proportion of labour income that is compensated for by a benefit) or a combination of these two aspects (Ray et al., 2010; Thévenon, 2011). In their novel approach to approximating leave accessibility, Dobrotić and Blum (2020) assess policies based on entitlement principles (citizenship-based versus employment-based benefits) and eligibility criteria, which they frame under the concept 'inclusiveness' of leave rights. Accordingly, their approach conceives accessibility to leave benefits as a separate and distinct dimension from the generosity concept, with the latter being instead referred to as benefit levels and the benefit payment duration.

In this article, we will map the development of indicators that seek to compare parenting leave policies in mature welfare states. We will also analyse their potential and pitfalls regarding the methodological approach as well as to their use in studies examining the socially stratifying and gendering effects of leave policies. Rather than adding to the multitude of existing indicators, the original contribution of this article to existing literature is a critical overview of the different types of indicators, as well as outlining new avenues for future research on leave policies. We will follow the mainstream literature and use the term 'generosity' in its broad sense, including benefit accessibility, benefit duration and the level of benefit payments.

\section{Studying Parenting Leave Policies: Operationalisations and Measurements}

Parenting leave policies fall under umbrella terms that include policies enabling parents to provide care for their children. Most commonly, this includes maternity leave, paternity leave, parental leave, childcare leave and leave for sick children. In the current article, the focus is on the three most commonly discussed forms: maternity, paternity and parental leave. Maternity leave is typically available to working mothers as a health and welfare measure that is "taken just before, during and immediately after childbirth" (Koslowski et al., 2020, p. 6). Paternity leave is targeted at fathers, and usually "taken soon after the birth of a child, and intended to enable the father to spend time with his partner, new child and [where this applies] older children" (Koslowski et al., 2020, p. 6). Parental leave is available to both mothers and fathers. It can take different forms, including a non-transferable individual right, an individual right that can be transferred to the other parent, or a family right that parents can divide between themselves as they wish (OECD, n.d.-b). Parental leave is meant to provide time for childcare and working parents can make use of it after maternity or paternity leave, either on a full-time or a part-time basis and until the child reaches a specific age. In some countries, however, parental leave benefit is available to economically inactive or unemployed parents from the date of childbirth (Dobrotić \& Blum, 2020).

The first parenting leave indicators were created of the blueprint designed for policies covering 'old social risks.' Therefore, we follow the main trends in the development of comparative social policy indicators and the way in which they have been used to compare parenting leave policies. In line with the literature, we distinguish between social expenditure, social rights and benefit recipiency indicators, and classify them in two levels: macro and micro (see Figure 1). Whilst macro-level indicators are intended to compare policies across countries, micro-level indicators allow comparison between individuals and households. Where micro-level data is aggregated to the national level, it can nevertheless also serve to describe differences between countries. The following sections will elaborate on the different types of indicators at these two levels.

\subsection{Macro-Level Indicators}

Two main types of indicators have been used to compare the generosity of public welfare benefits: social 


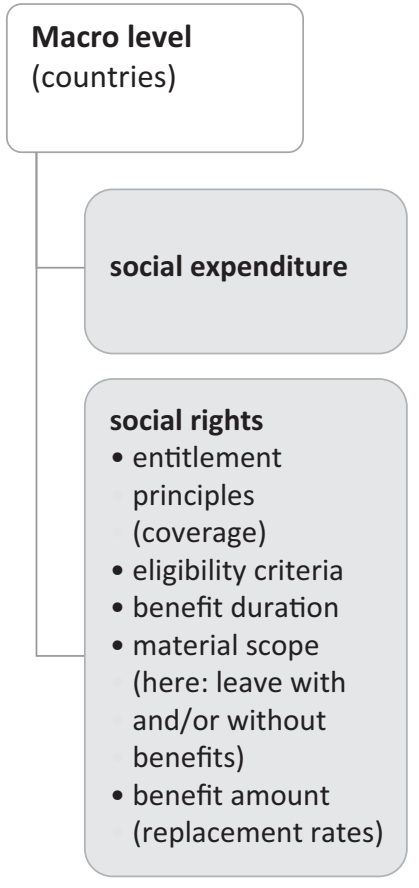

Figure 1. Indicators of leave generosity.

expenditure and social rights. These two types have also been adopted by researchers studying parenting leaves. In terms of conceptualisation, both indicators generally seek to approximate the extent of statutory leave benefits. However, there are considerable differences between them beyond this general analytical focus. Social expenditure is commonly represented by a single value, indicating either the actual public expenditure on a particular policy programme or a value relative to GDP. Although social rights can be represented by a single indicator (e.g., replacement rate), they are often compiled into a composite indicator, resulting in an index that captures the complex interplay between several aspects of a policy programme. Social expenditure and social rights indicators also differ in the scope of their research objectives. In contrast to social expenditure, many existing social rights-based indexes for leave policies also aim to capture the extent to which these rights are geared towards reducing gender inequality (Ciccia \& Verloo, 2012; Dobrotić \& Blum, 2020; Javornik, 2014; Javornik \& Kurowska, 2017; Ray et al., 2010).

\subsubsection{Social Expenditure}

Social expenditure data approximates the budgetary 'welfare effort' or 'welfare commitment' that governments make to finance public social benefits. With this indicator, variation in policy generosity is an expression of differences in 'how much' is spent on a particular programme or on social welfare in general (Castles, 2002, 2009). The indicator has been widely used in research into public social benefit schemes. It has been used either as a dependent variable (Clasen \& Siegel, 2007; Kittel \& Obinger, 2003) or an independent variable, in the

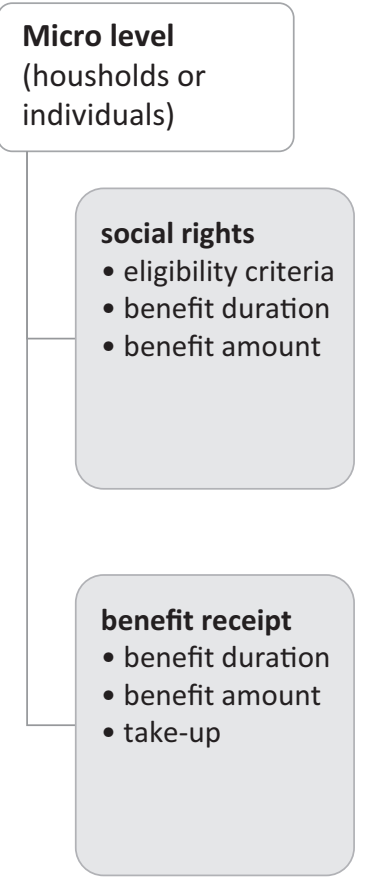

latter case to study, for example, public attitudes, political participation or wellbeing (for a short overview see Kunißen, 2019). However, it has been less used in the context of leave policies (Luci-Greulich \& Thévenon, 2013).

The size of social expenditure encompasses all dimensions of the generosity concept. The amount of social expenditure is affected by the extent of the population that receives the benefits, which is in turn determined by the eligibility conditions. For example, in two countries with identical leave benefit amounts per recipient, social expenditure will be higher in the country with citizenship-based entitlements to leave than in the one with employment-based entitlements. Social expenditure is also influenced by the duration of the benefit payment. As a similar example, social expenditure will be higher in the country with a longer benefit payment duration. Lastly, social expenditure is also influenced by the amount of the benefit per recipient. There are also other factors such as take-up that affect the total amount of social expenditure. However, these are not determined by the design of the policy, but by its attractiveness to potential recipients.

Consequently, social expenditure data provides a simple summary of the overall policy design and policy implementation within a specific context. Nonetheless, there are some shortcomings that researchers should be aware of when using this indicator in comparative studies. Since social expenditure is affected by the size of the population that receives the benefit, it should be corrected for the size of the eligible population (De Deken \& Kittel, 2007; Kangas \& Palme, 2007; Scruggs, 2007); for example, by dividing spending by the proportion of parents with dependent children of a given age. However, this approach is problematic, as it might be difficult to 
find an appropriate variable to approximate the eligible population and to do so across different contexts (van Oorschot, 2013, p. 228).

Another shortcoming lies in the use of GDP as a factor used to adjust for national differences in wealth, as the comparability of the values may be compromised if GDP fluctuates. To compensate for this, spending can also be measured as absolute amounts expressed in purchasing power parities (PPP). In Figure 2, we display unadjusted social expenditure data expressed as a percentage of GDP. Using this indicator, countries such as Estonia, Hungary, Sweden, Finland and the Czech Republic are shown as having the most generous parental leave policies. By contrast, the United Kingdom, Austria, Switzerland, the Netherlands, Ireland and Spain stand out as having the least generous policies. In Figure 3, we show the amount of spending on leave policies, adjusted for the number of live births and expressed in PPP. Estonia, Sweden, Finland and the Czech
Republic are joined by Denmark at the top of the ranking, Hungary appears less generous, and Luxembourg shows the most generous system. At the bottom end of the ranking, the same countries appear to be the least generous: United Kingdom, Austria, Switzerland, the Netherlands, Ireland and Spain. Although adjusting for the eligible population does produce a more nuanced picture, the correlation between the two measurements is very strong $(r=0.80)$. Probably the most pressing issue with the social expenditure data is the fact that it does not provide information on who is supposed to receive or actually does receive a benefit. This can have implications for gender equality-something that is of particular interest in parental leave research.

\subsubsection{Social Rights}

Expenditure data has considerable limitations for the study of policy design and its effect on specific policy

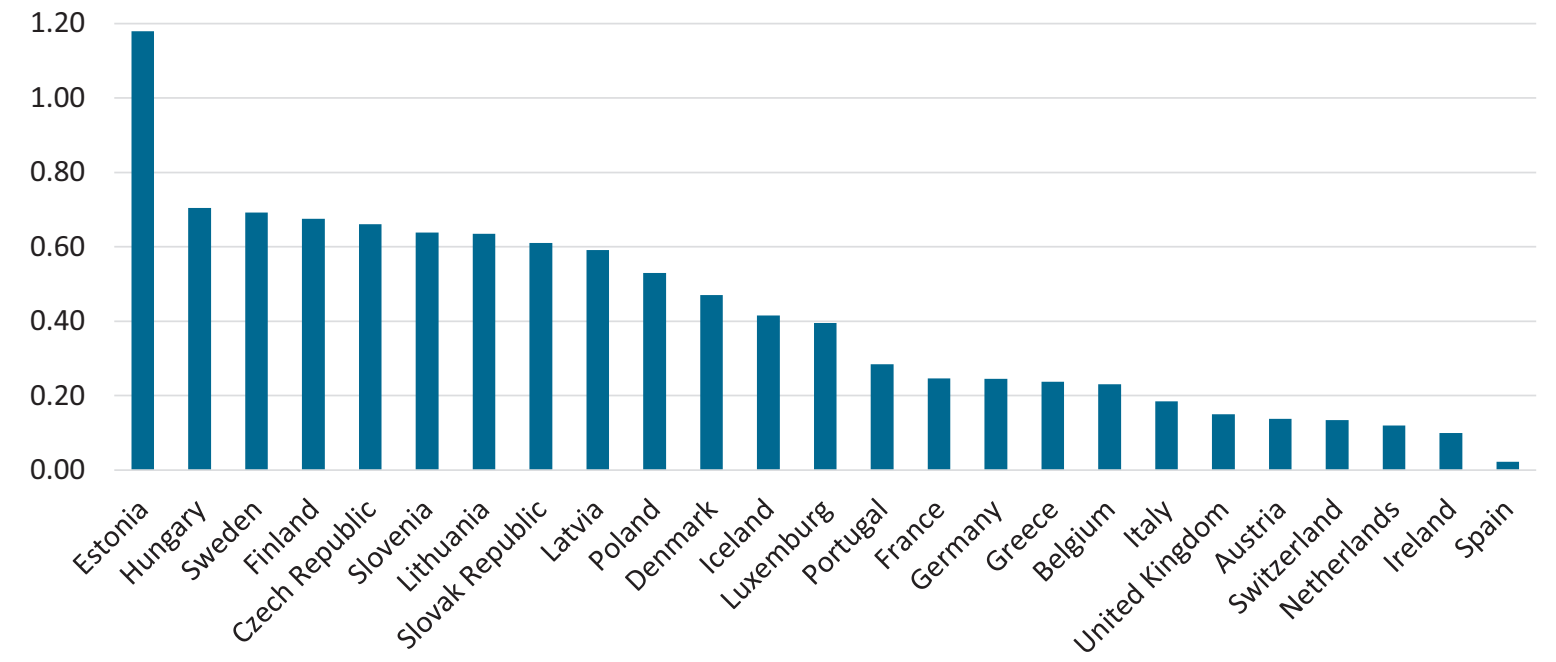

Figure 2. Total public expenditure on maternity and parental leave, as a percentage of GDP, 2015. Source: Authors' calculations based on OECD (n.d.-a).

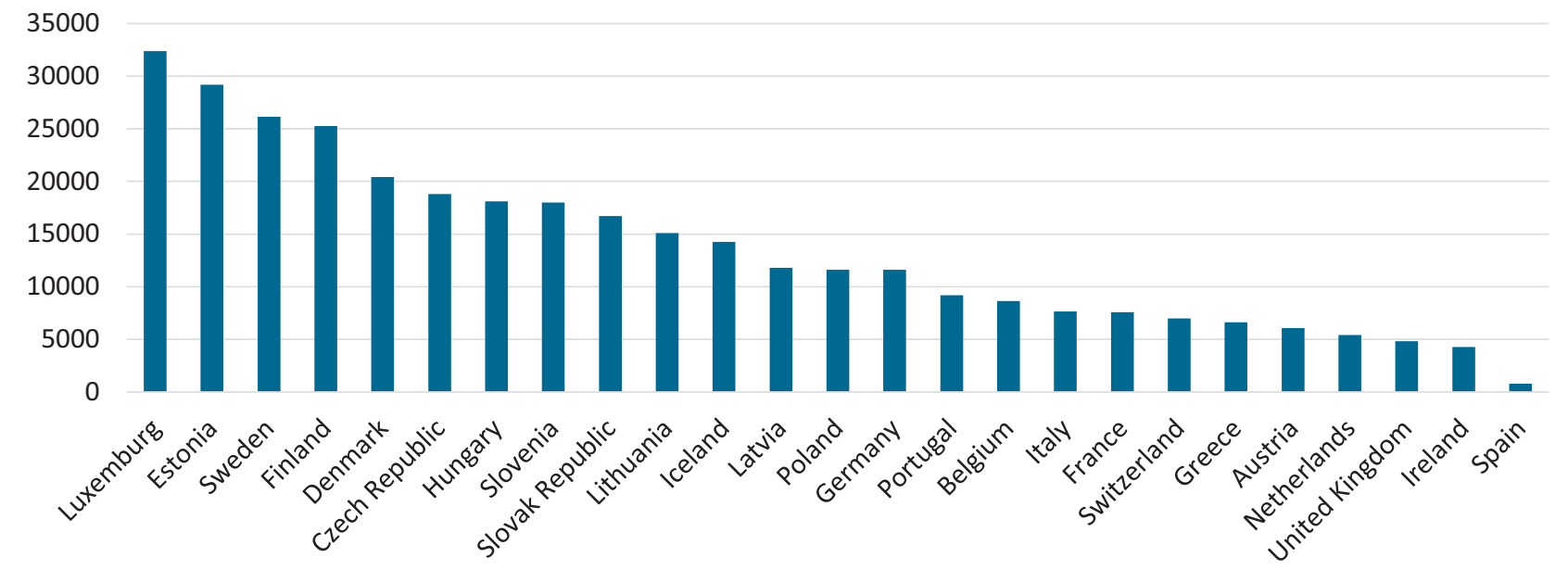

Figure 3. Public expenditure on maternity and parental leaves per live birth, in USD 2010 PPP, 2015. Data for Greece and Poland refer to 2012. Source: OECD (n.d.-b). 
outcomes (e.g., stratification and gender equality). Social rights indicators were developed as an alternative measurement of the extent of 'welfare commitment.' Social rights data can be both quantitative and qualitative, but in this review, we only focus on the quantitative indicators. These social rights indicators are a result of quantification processes that combine legislative information on specific policy programmes with hypothetical or so-called model households. These model households assume specific values for wages (average or median) for a standard work contract in a particular sector. They also specify a particular intensity of employment for the household members and the household size. The model household is set for each database, although some databases calculate social rights indicators for several types of model households (e.g., the OECD Family Database). Since the model household is constant across countries, this approach provides a high degree of crosscountry comparability between policy designs and their outcomes in terms of replacement rates.

The social rights data comprises several indicators. In the context of parenting leave, the most common indicators are the leave duration and the replacement rate. For example, the Parental Leave Benefit dataset (Nelson et al., 2020) provides data on maternity, paternity and parental leave duration, gross and net benefit levels, and replacement rates. The data covers 34 countries for the period between 1950 and 2015, with five-year data collection intervals. Another example with comparable information that is still being updated is the OECD Family Database (OECD, n.d.-c). Other databases are no longer kept up to date but still contain valuable data, such as the Multilinks Database on Intergenerational Policy Indicators (Multilinks, 2011), the Family Policy Database (Gornick, Meyers, \& Ross, 1997), and the Comparative Maternity, Parental and Childcare Leave and Benefits Database (Gauthier, 2011). However, none of these databases have attempted to quantify the accessibility of parenting leave benefits as an important dimension of the generosity concept. This gap in the literature has been recently pointed out by Dobrotić and Blum (2019, 2020). They addressed the issue by introducing an eligibility index that quantifies the accessibility of parental leave benefits on the basis of entitlement principles (citizenship-based or employment-based) and eligibility conditions (e.g., qualifying period).

Figures 4 and 5 provide examples of social rights data drawn from the OECD Family Database. They show, respectively, the number of weeks of total paid leave available to mothers and the average payment rate (as a percentage of gross earnings of a model family with two adult earners and two children) for OECD countries in 2018. These two indicators refer to benefit duration and benefit levels as two aspects of leave generosity. Examining leave duration in Figure 4, Estonia, Slovakia, Finland and Hungary are shown as having the most generous leave policies. By contrast, Switzerland, the Netherlands, Spain, Iceland and Ireland appear as the least generous. Again, most countries consistently rank high or low in terms of leave generosity, and the correlation of this indicator with spending on leave policies (Figure 2 ) is strong $(r=0.75)$. At the same time, the differences between this example of a social rights indicator and the social expenditure approach become clear. For instance, countries such as Sweden and especially Iceland score higher in terms of social expenditure, while Austria appears more generous in terms of the paid leave duration available to mothers. Figure 5 shows yet another ranking. In terms of average payment rates, Finland and France appear the least generous, while Lithuania, the Netherlands and Spain are shown as being the most generous. This is the result of the availability of 16 weeks of maternity benefits paid at 100 percent of the previous labour income in both Spain and the Netherlands, while parental leave is unpaid. In many other countries, average payment rates (calculated on the basis of paid maternity and parental leave rights) are lower, but in reality, women are entitled to benefits for a longer period of time. The correlation of average payment with public spending (Figure 2 ) is negligible

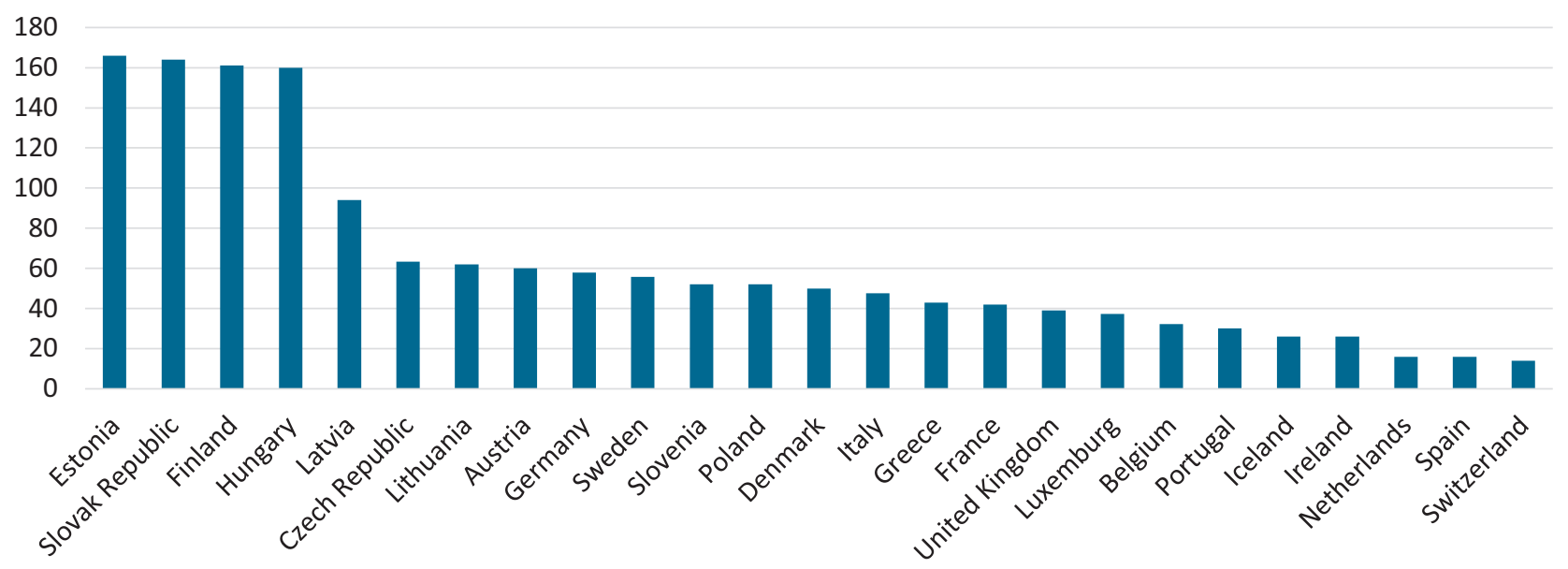

Figure 4. Number of weeks of total paid leave available to mothers. Source: OECD (n.d.-b) for 2018. 


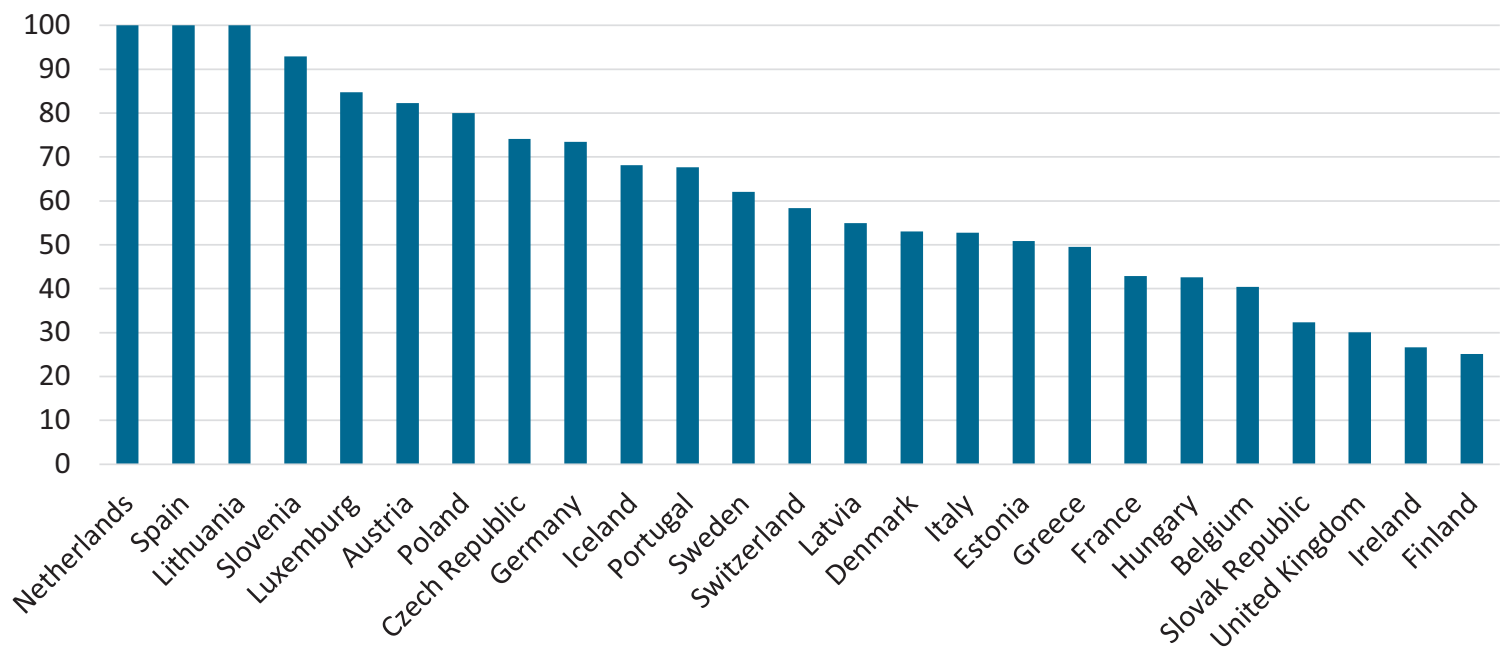

Figure 5. Average payment rates available to mothers as a percentage of previous wages. Source: OECD (n.d.-b) for 2018.

$(r=-0.09)$. This means that spending on leave policies appears to be associated more with the number of weeks of paid leave than with the level of the payment. Therefore, the high spending levels in Sweden or Iceland could be explained by high rates of take up, to which we turn further below.

The advantage of social rights indicators is that they provide a much more nuanced picture of public welfare provision with regard to policy design, and hence policy intension. Their use also offers more insight into who is supposed to receive the benefit. Additionally, where the indicators are linked to socio-economic and gender equality aspects (e.g., Ciccia \& Verloo, 2012; Javornik, 2014; Javornik \& Kurowska, 2017; Ray et al., 2010), social rights data also sheds light on the socially stratifying and gendered outcomes these policies can produce.

The limitation of social rights data mainly lies in the use of model households. The extent to which these are representative of real populations has been questioned, as has to what extent the prevalence of these model households varies across countries (Gallie \& Paugam, 2000). Furthermore, where average net replacement rates are used to study trends in policies, wage developments and tax policies are ignored and the generosity of replacement rates can easily be misinterpreted. There is also a discrepancy between nominal entitlement, benefit administration and actual take-up rates. Social rights data is unable to reflect this; however, it can be expected to affect the actual realisation of social rights. Further, the social rights approach usually does not have the capacity to take income and benefit ceilings into account. This can lead to overestimating the generosity of the leave benefits. On top of this, the aspect of time is usually disregarded in such an approach. For example, a replacement rate that is initially relatively high but decreases shortly after or is only paid for a few weeks in a year may in the end be less generous than a benefit with a continuously paid lower replacement rate that is paid for an entire year or longer. Lastly, when qualitative information on benefit rights is quantified and included in com- posite indicators (e.g., Dobrotić \& Blum, 2020), coding and weighting the different components can be crucial. Hence, decisions about how to attribute scores to different qualitative information and how to weight one component relative to another not only have to be suitably justified, but also require sensitivity analyses and careful interpretation.

Two recent sources of social rights data attempt to deal with a number of these shortcomings. The OECD Family Support Calculator, for example, allows us to compare leave policy entitlements based on the characteristics of a wide range of individuals and households, taking the heterogeneity of the population into account (OECD, n.d.-d). A similar model-family approach termed the Hypothetical Household Tool (HHoT) is now also available in EUROMOD (Hufkens et al., 2019). This is a microsimulation tool that is based on the EU Survey on Income and Living Conditions (EU-SILC) and allows the calculation and observation of the statutory leave entitlements for a wide array of hypothetical households that can be specified by the user. The HHoT also allows us to take into account the interaction with wage developments and tax policies. Such an approach is ideally suited for between-country comparisons and allows the computation of policy indicators for a wide range of households. Nevertheless, it does not solve the issue of representativeness of the population.

\subsection{Micro-Level Indicators}

To date, micro-level data has been a relatively underused source of information in assessing the generosity of leave benefits. Dominant examples of micro-level indicators are based on social rights and on benefit receipt data. Given the nature of the data, these indicators are not only suitable to study the generosity of parenting leave benefits but also their stratifying and gendering effects. They could be used to statistically model, for example, the association between benefit amounts and gender or education. This is a huge advantage over the approaches 
we have discussed so far. Furthermore, the combination of microsimulation with benefit receipt data can estimate the degree of non-take-up with considerable precision. The use of micro-level data can therefore not only reveal the socio-economic profile of parents who miss out on support from child-related leave programmes, but also of parents who are targeted by these policies yet are not using them. Consequently, such data can provide valuable insights into the effectiveness of policy designs and is an important source of information for policy reforms and policy learning.

\subsubsection{Social Rights}

Social rights are commonly accepted as macro-level indicators that capture the characteristics of policy designs in terms of legal provisions. Less attention is paid to their ability to link macro-level policy designs with microlevel social reality. This has only been possible in recent years with the increasing availability of comparative legislative data on policy design, such as the Mutual Information System on Social Protection (MISSOC) or the International Reviews on Leave Policies and Related Research produced by the International Network on Leave Policies \& Research (LP\&R), and rich comparative social survey data such as the EU-SILC. To overcome some of the shortcomings of the previously mentioned macrolevel indicators, scholars have used imputation methods to assess who should-based on national leave policy regulations-receive a benefit, for how long and what amount. This data can either be aggregated to formulate a single-value parenting leave indicator or can be used at the individual level to analyse the variation in eligibility and entitlements, both within and across countries.

One of the earliest examples of the application of this method to parenting leave data is a study by Zabel (2008), who simulated maternity leave for women using the British Household Panel Survey. Comparable with this, EUROMOD introduced parenting leave policies in their tax-benefit simulation models mapping the position of eligible individuals in the EU-SILC sample (Immervoll, O'Donoghue, \& Sutherland, 1999). More-recent attempts include the simulation of leave entitlements such as parental leave benefits for a few European countries (Avram \& Popova, 2020; Popova \& Navicke, 2020). EUROMOD is also modelling parenting leave entitlements for parents in the EU-SILC sample. This allows us to measure and compare the stability of leave benefits across the duration of the benefits (e.g., if the leave design provides more-generous payments for the first months of leave). This is unique and a distinct feature of the EUROMOD approach, nevertheless, some limitations are apparent. First, only leave entitlements that are part of the tax-benefit system can be included. In cases where leave is unpaid or payment is arranged through private insurance, it cannot be programmed into the model. Second, this particular microsimulation approach is subject to a selection effect. It does not account for the possibility that some people may opt out of or postpone parenthood due to unfavourable economic conditions that are not alleviated by the support provided by the parenting leave programme. It also does not provide the distribution of social rights that are fully comparable across countries but where the profile of parents considerably differs.

Bártová and Emery (2018) used an approach similar to the one of EUROMOD by applying microsimulation methods for a population of women of childbearing age and therefore 'at risk' of giving birth. This approach allows us to observe the distribution of social rights to parenting leave across the whole population that is realistically subject to the possibility of experiencing the relevant social risk. By design, this microsimulation approach provides direct insight into the generosity of parenting leave policies as illustrated in Figure 6 . This shows the proportion of women between the age of 20 and 40 who would be eligible either to maternity leave, parental leave or both, if they were to have a child in that particular year. Although the expenditure data presented in Figures 2 and 3 is influenced by the actual number of parents receiving the benefit in a given year, Figure 6 is based on a hypothetical situation of all women between the age of 20 and 40 giving birth in 2008. Therefore, the two types of data cannot be directly compared. Nonetheless, it points to some substantial differences in the country outcomes with respect to generosity. For instance, Austria appears as highly generous on the eligibility indicator, with maternity and/or parental benefits being available to all women who give birth. By contrast, when using expenditure data to evaluate leave generosity, Austria turns out to be among the least generous countries. The outcome is different even when using the indicator of the number of weeks of total paid parental leave, where it falls somewhere in the middle.

Microsimulation has also been applied to the amount of cash benefits, and thanks to its link with survey data, it can easily be broken down by socio-economic status and other characteristics (Bártová, 2017; Bártová \& Emery, 2018). Another advantage of this approach is that it allows us to study the policy outcomes for populations that are at lower risk of becoming parents. Using these hypothetical parents among the population of teenagers, single women or single men enables us to understand the situation of teenage mothers or single fathers who may be overlooked when using conventional methods. Nonetheless, the microsimulation approaches also have their limitations. A key assumption underlying microsimulation benefit models is that of full take-up: It is assumed that anyone who is entitled to a benefit actually claims it. The approach therefore only approximates social rights to potential benefit recipients. In the field of family policies in general, and parental leave policies in particular, such an assumption is unrealistic. It is well documented that leave entitlements are underused, with strong gender and socio-economic cleavages in its uptake (Ghysels \& Van Lancker, 2011; Ray et al., 2010). 


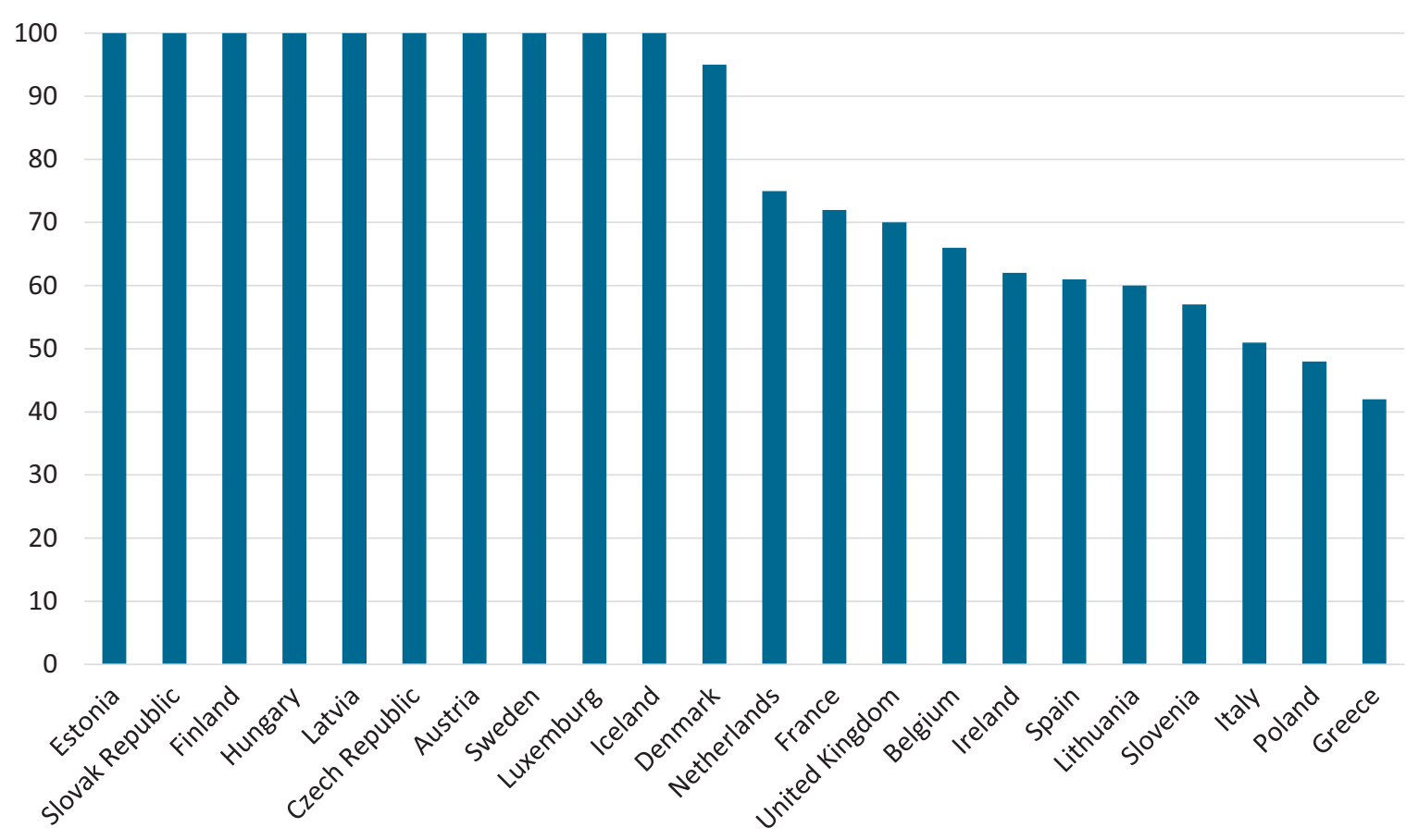

Figure 6. Percentage of women (20-40 years) who would be eligible for a parental leave benefit were they to give birth in 2008. Source: Bártová (2017).

\subsubsection{Benefit Receipt}

A last set of indicators draw on benefit receipt to compare the extent of public welfare provision across different target populations (individuals and households within a country, and different country populations) and over time (De Deken \& Clasen, 2011, 2013; Otto, 2018; van Oorschot, 2013). Data on benefit receipt is usually sourced from administrative or survey data that is reported at an individual and/or household level. In contrast to social rights data, benefit access is not a hypothetical entitlement. Depending on the unit of analysis, more accessible benefits translate into a higher proportion of individuals or households receiving the benefit or taking up leave, relative to a specific target population. For example, in the case of parental leave, micro-level information on leave benefit receipt is put in relation to the number of people with young dependent children. These take-up rates can also be compared across countries. Likewise, benefit amounts are not hypothetical or case-typical replacement rates, but are expressed either through directly reported amounts, or as the proportion of a reported benefit relative to a reference income. The latter is more suitable for comparing regions or countries. Where the data is available, benefit receipt could also be operationalised as the duration for which a benefit is received.

Although some studies have already used administrative records to gauge the take-up of different types of leaves in particular countries (Kil, Wood, \& Neels, 2018; Koslowski \& Kadar-Satat, 2019; Marynissen, Mussino, Wood, \& Duvander, 2019), comparative studies are scarce (for an exception see Karu \& Tremblay, 2018).
The problem is that administrative records are not available in most countries, and where they are, the concepts of leave use are not always comparable. Administrative records are based on administrative definitions of policies and statutory entitlements, tied to the laws and (social security) programmes of the country under study. Accordingly, the need population can be different, the way of classifying and recording take-up can be different, and these categories can vary over time when policies change (De Deken \& Clasen, 2013; Otto, 2018). In that sense, harmonised cross-country survey data offers better prospects to examine leave uptake across countries and over time. Comparing the take-up of leave of a particular household with the respective social rights entitlements would even allow us to estimate the amount of non-take up in leave use. However, crosscountry harmonised surveys in which the use of leave is properly recorded are rare, as respondents are often asked to describe their labour market status during the past week or at the time of the survey, rather than in terms of labour market status in the period after birth. Furthermore, for many countries it is not possible to isolate maternity leave benefits from child benefits, or parental leave benefits from unemployment or sickness benefits (Zardo-Trindade \& Goedemé, 2020). The EU Labour Force Survey (EU-LFS) has so far included three ad hoc modules on the reconciliation of work and family life in 2005, 2010 and 2018. In this module, detailed questions are asked about childcare use, the use of leave and the use of career break schemes with regard to the youngest child living in the household. Unfortunately, the questions and the selection of the relevant population changed over time, which severely 
hampers comparability. Moreover, it is not always clear how respondents interpreted the questions, in particular in systems in which there is no clear distinction between maternity and parental leave (e.g., the Nordic countries). As a result, only a few studies have used this data to examine social inequalities in leave take-up (Ghysels \& Van Lancker, 2011; Van Lancker, 2017) or to model the probability to work by individual take-up of leave (Van Lancker, 2018).

Using the EU-LFS ad hoc module of 2018, Figure 7 shows the proportion of women between 18 and 64 years old taking care of children living in the household. It shows how different benefit design aspects can translate into actual use of these policies. According to this data, countries such as Austria, Sweden, Slovakia, Czech Republic, Estonia and Finland appear the most generous, while countries such as Switzerland, Portugal, Spain and the Netherlands appear the least generous. Again, the country ranking does not change substantially for most countries, and the correlation with public expenditure is strong $(r=0.68)$. In generous countries such as Sweden, Estonia, Slovakia and Czech Republic, spending on leave benefits is high (Figures 2 and 3 ), all women of child-bearing age are eligible (Figure 6) and social rights are usually generous as well (in terms of the number of paid weeks available and/or payment rates; see Figures 4 and 5). This translates into high levels of take-up. Vice versa, in countries such as Spain or the Netherlands, spending is low, fewer women of childbearing age are eligible for leave, parental leave is unpaid and take-up rates are low. Some countries, however, change ranks. In Austria, for example, spending on leave is relatively low whereas both eligibility and take-up rates are high. One reason could be the fact that in Austria, the class and gender inequalities in use are substantial, with only few fathers taking up leave, while in countries with comparable features such as Sweden such inequalities are more modest (see Koslowski et al., 2020). Although beyond the scope of the present article, further analysis using microlevel social rights and benefit recipient indicators would allow such questions to be answered.

\section{Conclusion}

In this article, we have reviewed various approaches to the comparative study of the generosity of leave benefits based on social expenditure, social rights and benefit recipiency data. These indicators enabled us to analyse and compare the degree to which parenting leave policies are generous in terms of their budgetary volume, their accessibility, the duration of leave, the (relative) amounts of leave benefits and leave benefit receipt.

We systematically separated the various indicators into two categories, depending on whether they were constructed on the macro or micro level, and we highlighted the many difficulties and pitfalls involved in measuring and operationalising the generosity of leave policies. Although some countries consistently rank high or low in terms of generosity, the devil is in the details. We showed how the operationalisation of leave policies at macro and micro levels according to different approaches can lead to different rankings, interpretations and qualifications of countries and leave systems. We found that most of the parenting leave indicators that are commonly used measure only the benefit duration and the amount of cash benefits. This is in line with previous criticism of the existing policy indicators (Dobrotić \& Blum, 2019, 2020). It could be argued that social expenditure data provides information about generosity, because it constitutes the outcome of access to benefits, their duration and amount. However, it is very difficult to disentangle each component of the generosity concept and assign a specific value or a proportion of the total expenditure to each component. Social

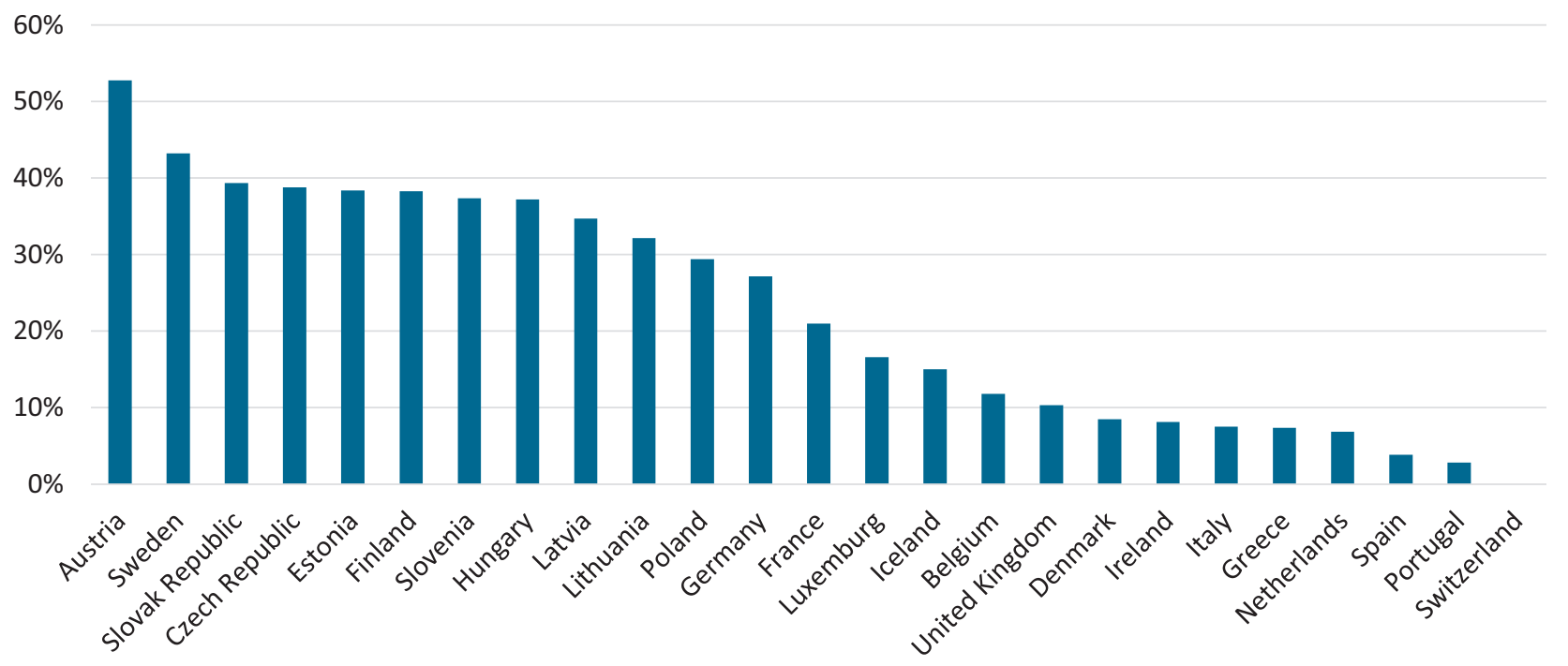

Figure 7. Proportion of respondents (18-64 years) having used parental leave for their youngest child. Source: Authors' own calculations based on the EU-LFS 2018 ad hoc module. 
expenditure data also does not provide information on who actually receives the benefits, and consequently is not suitable for use in studies on the stratifying or gendering effects of leave policies. Social rights indicators constructed on the macro level provide a standardised and more detailed way to compare policy designs across countries and time. This is because they are built on the social rights of model households. Nonetheless, the use of model families is also the main reason why this approach has been criticised. It has raised questions about how representative they are in contemporary societies, and to what extent standardised model families equally prevail across countries. This criticism does not stem from the inability of social rights indicators to effectively measure varying social policy designs, but instead from its broad-brush approach that is not suitable for all research questions (Siegel, 2007).

We found that indicators based on data for benefit recipiency and social rights that are measured on the micro-level can provide a much better opportunity for analysing the generosity of parenting leave benefits. In contrast to the macro-level indicators, micro-level indicators have the ability to provide policy indicators for each dimension of the generosity concept. The micro-level social rights indicators create a link between the national legislation on parenting leave and the individual characteristics of survey respondents by means of microsimulation. This offers an insight into the distribution of social rights in real populations and their effect on social stratification and gender inequality. However, the approach is limited because it does not offer any information about the actual use of leave policies. This limitation is addressed by benefit recipiency data, which captures the actual take-up of benefits. Nevertheless, in this regard also, issues of comparability are important, as the operationalisation of benefit receipt or leave use is often linked to country-specific legislation. While headway can and must be made in terms of the availability and quality of data based upon harmonised cross-country databases, there is no one-sizefits-all indicator that adequately captures all the dimensions that are relevant to leave research.

Against this background, we would like to stress that the choice of the indicator very much depends on the exact research question one seeks to address, and how this choice can be theoretically underpinned. Where a more comprehensive understanding of leave policies in different national contexts and across time is needed, ideally different indicators should be combined.

\section{Acknowledgments}

The research was partially funded by the European Union's Horizon 2020 research and innovation programme (MSCA IF No. 893008). We would also wish to express our gratitude to the three reviewers and the editors of this thematic issue, whose comments have helped us improve the article.

\section{Conflict of Interests}

The authors declare no conflict of interests.

\section{References}

Avram, S., \& Popova, D. (2020). Do welfare state taxes and transfers reduce gender income inequality? Evidence from eight European countries (EUROMOD Working Paper EM9/20). Colchester: Institute for Social and Economic Research.

Bártová, A. (2017). 'Genderising' aspects of birth-related leave policies and fertility behaviour in Europe: Understanding policy from an individual's perspective (Unpublished Doctoral dissertation). University of Edinburgh, Scotland.

Bártová, A., \& Emery, T. (2018). Measuring policy entitlements at the micro-level: Maternity and parental leave in Europe. Community, Work \& Family, 21(1), 33-52.

Bonoli, G. (2005). The politics of the new social policies: Providing coverage against new social risks in mature welfare states. Policy \& Politics, 33(3), 431-449.

Bruning, G., \& Plantenga, J. (1999). Parental leave and equal opportunities: Experiences in eight European countries. Journal of European Social Policy, 9(3), 195-209.

Castles, F. G. (2002). Developing new measures of welfare state change and reform. European Journal of Political Research, 41(5), 613-641.

Castles, F. G. (2009). What welfare states do: A disaggregated expenditure approach. Journal of Social Policy, 38(1), 45-62.

Ciccia, R., \& Verloo, M. (2012). Parental leave regulations and the persistence of the male breadwinner model: Using fuzzy-set ideal type analysis to assess gender equality in an enlarged Europe. Journal of European Social Policy, 22(5), 507-528.

Clasen, J., \& Siegel, N. A. (2007). Comparative welfare state analysis and the 'dependent variable problem.' In J. Clasen \& N. A. Siegel (Eds.), Investigating welfare state change. The 'dependent variable problem' in comparative analysis (pp. 3-12). Cheltenham: Edward Elgar.

De Deken, J., \& Clasen, J. (2011). Tracking caseloads: The changing composition of working-age benefit receipt in Europe. In J. Clasen \& D. Clegg (Eds.), Regulating the risk of unemployment: National adaptations to post-industrial labour markets in Europe (pp. 297-317). Oxford: Oxford University Press.

De Deken, J., \& Clasen, J. (2013). Benefit dependency: The pros and cons of using "caseload" data for national and international comparisons. International Social Security Review, 66(2), 53-78.

De Deken, J., \& Kittel, B. (2007). Social expenditure under scrutiny: The problems of using aggregate spending data for assessing welfare state dynamics. In J. Clasen \& N. A. Siegel (Eds.), Investigating welfare state 
change. The 'dependent variable problem' in comparative analysis (pp. 72-104). Cheltenham: Edward Elgar.

Dobrotić, I., \& Blum, S. (2019). A social right? Access to leave and its relation to parents' labour market position. In P. Moss, A.-Z. Duvander, \& A. Koslowski (Eds.), Parental leave and beyond. Recent international developments, current issues and future directions (pp. 261-279). Bristol: Policy Press.

Dobrotić, I., \& Blum, S. (2020). Inclusiveness of parentalleave benefits in twenty-one European countries: Measuring social and gender inequalities in leave eligibility. Social Politics: International Studies in Gender, State \& Society, 27(3), 588-614.

Gallie, D., \& Paugam, S. (2000). Welfare regimes and the experience of unemployment in Europe. Oxford: Oxford University Press.

Gauthier, A. H. (2011). Comparative Family Policy Database: Version 3 [Computer File]. Max-PlanckInstitute for Demographic Research. Retrieved from https://www.demogr.mpg.de/cgi-bin/databases/ FamPolDB/index.plx

Ghysels, J., \& Van Lancker, W. (2011). The unequal benefits of activation: An analysis of the social distribution of family policy among families with young children. Journal of European Social Policy, 21(5), 472-485.

Gornick, J. C., Meyers, M. K., \& Ross, K. E. (1997). Supporting the employment of mothers: Policy variation across fourteen welfare states. Journal of European Social Policy, 7(1), 45-70.

Hufkens, T., Goedemé, T., Gasior, K., Leventi, C., Manios, K., Rastrigina, O., . . . Verbist, G. (2019). The hypothetical household tool (HHOT) in EUROMOD: A new instrument for comparative research on taxbenefit policies in Europe. The International Journal of Microsimulation, 12(3), 68-85.

Immervoll, H., O'Donoghue, C., \& Sutherland, H. (1999). An introduction to EUROMOD (EUROMOD Working Paper No. EM0/99). Colchester: Institute for Social and Economic Research. Retrieved from https://www.iser.essex.ac.uk/files/msu/emod/ workingpapers/emwp0.pdf

Javornik, J. (2014). Measuring state de-familialism: Contesting post-socialist exceptionalism. Journal of European Social Policy, 24(3), 240-257.

Javornik, J., \& Kurowska, A. (2017). Work and care opportunities under different parental leave systems: Gender and class inequalities in Northern Europe. Social Policy \& Administration, 51(4), 617-637.

Kangas, O., \& Palme, J. (2007). Social rights, structural needs and social expenditure: A comparative study of 18 OECD countries 1960-2000. In J. Clasen \& N. A. Siegel (Eds.), Investigating welfare state change. The 'dependent variable problem' in comparative analysis (pp. 106-129). Cheltenham: Edward Elgar.

Karu, M., \& Tremblay, D. G. (2018). Fathers on parental leave: An analysis of rights and take-up in 29 countries. Community, Work \& Family, 21(3), 344-362.

Kil, T., Wood, J., \& Neels, K. (2018). Parental leave uptake among migrant and native mothers: Can precarious employment trajectories account for the difference? Ethnicities, 18(1), 106-141.

Kittel, B., \& Obinger, H. (2003). Political parties, institutions, and the dynamics of social expenditure in times of austerity. Journal of European Public Policy, 10(1), 20-45.

Koslowski, A., Blum, S., Dobrotić, I., Kaufman, G., \& Moss, P. (2020). (Eds.). International review of leave policies and research 2020. Hagen: Fakultät für Kultur- und Sozialwissenschaften. Retrieved from http://www. leavenetwork.org/lp_and_r_reports

Koslowski, A., \& Kadar-Satat, G. (2019). Fathers at work: Explaining the gaps between entitlement to leave policies and uptake. Community, Work \& Family, 22(2), 129-145.

Kunißen, K. (2019). From dependent to independent variable: A critical assessment of operationalisations of 'welfare stateness' as macro-level indicators in multilevel analyses. Social Indicators Research, 142(2), 597-616.

Luci-Greulich, A., \& Thévenon, O. (2013). The impact of family policies on fertility trends in developed countries. European Journal of Population, 29(4), 387-416.

Marynissen, L., Mussino, E., Wood, J., \& Duvander, A.-Z. (2019). Fathers' parental leave uptake in Belgium and Sweden: Self-evident or subject to employment characteristics? Social Sciences, 8(11). https://doi.org/ 10.3390/socsci8110312

Moss, P., \& Deven, F. (2019). Leave policies in Europe: Current policies, future directions. International Journal of Sociology and Social Policy, 40(5/6), 429-440.

Multilinks. (2011). Multilinks Database on Intergenerational Policy Indicators: Version 2.1 [Data set]. Retrieved from http://multilinks-database.wzb.eu

Nelson, K., Fredriksson, D., Korpi, T., Korpi, W., Palme, J., \& Sjöberg, O. (2020). The social policy indicators (SPIN) database. International Journal of Social Welfare, 29(3), 285-289.

OECD. (n.d.-a). Social expenditure database [Data set]. Public policies for families and children. Retrieved from https://www.oecd.org/social/expenditure.htm

OECD. (n.d.-b). OECD family database: Indicators. PF2.1: Key characteristics of parental leave systems [Data set]. Retrieved from http://www.oecd.org/els/soc/ PF2_1_Parental_leave_systems.pdf

OECD. (n.d.-c). OECD family database: Indicators. OECD. Retrieved from https://www.oecd.org/els/family/ database.htm

OECD. (n.d.-d). OECD family database: The family support calculator. $O E C D$. Retrieved from http://www. oecd.org/els/soc/oecdfamilydatabasethefamily supportcalculator.htm\#calculator

Otto, A. (2018). A benefit recipiency approach to analysing differences and similarities in European welfare provision. Social Indicators Research, 137(2), 765-788. 
Popova, D., \& Navicke, J. (2020). Extending EUROMOD with parental leave benefits (PLBS): Deliverable 9.3 (InGRID-2 Output Project 730998-H2020). Leuven: KU Leuven.

Pronzato, C. D. (2009). Return to work after childbirth: Does parental leave matter in Europe? Review of Economics of the Household, 7(4), 341-360.

Ranci, C., Österle, A., Arlotti, M., \& Parma, A. (2019). Coverage versus generosity: Comparing eligibility and need assessment in six cash-for-care programmes. Social Policy \& Administration, 53(4), 551-566.

Ray, R., Gornick, J. C., \& Schmitt, J. (2010). Who cares? Assessing generosity and gender equality in parental leave policy designs in 21 countries. Journal of European Social Policy, 20(3), 196-216.

Scruggs, L. (2007). Welfare state generosity across space and time. In J. Clasen \& N. A. Siegel (Eds.), Investigating welfare state change. The 'dependent variable problem' in comparative analysis (pp. 133-165). Cheltenham: Edward Elgar.

Siegel, N. A. (2007). When (only) money matters: The pros and cons of expenditure analysis. In J. Clasen \& N. A. Siegel (Eds.), Investigating welfare state change. The 'dependent variable problem' in comparative analysis (pp. 43-71). Cheltenham: Edward Elgar.

Thévenon, O. (2011). Family policies in OECD countries: A comparative analysis. Population and Development
Review, 37(1), 57-87.

Van Lancker, W. (2017). The Matthew Effect Redux. Going beyond the mean in evaluating family policies. In B. Greve (Ed.), Handbook of social policy evaluation (pp. 431-455). Cheltenham: Edward Elgar.

Van Lancker, W. (2018). Does the use of reconciliation policies enable single mothers to work? A comparative examination of European countries. In R. Nieuwenhuis \& L. Maldonado (Eds.), Triple bind of single-parent families: Resources, employment and policies to improve wellbeing (pp. 239-261). Bristol: Policy Press.

van Oorschot, W. (2013). Comparative welfare state analysis with survey-based benefit recipiency data: The "dependent variable problem" revisited. European Journal of Social Security, 15(3), 224-249.

Zabel, C. (2008). Eligibility for maternity leave and first birth timing in Great Britain. Population Research and Policy Review, 28(3), 251-270.

Zardo-Trindade, L., \& Goedemé, T. (2020). The comparability of the EU-SILC income variables: Review and recommendations. Luxembourg: Publications Office of the European Union. Retrieved from https:// ec.europa.eu/eurostat/documents/3888793/ 10381811/KS-TC-20-001-EN-N.pdf/a4acc1b9ecc5-2049-9843-0f67677aab37

\section{About the Authors}

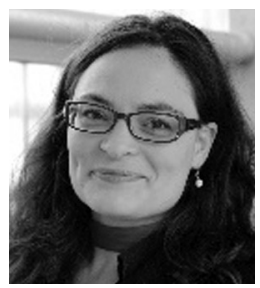

Adeline Otto is a Postdoctoral Researcher affiliated to the KU Leuven Centre for Sociological Research. In her research, she compares social policies across different European countries, with a special focus on the income distributional, employment and working conditions effects of social benefits. More recently, she also investigates eco-social policies, social inequalities and public attitudes in the transition to carbon-neutral societies.

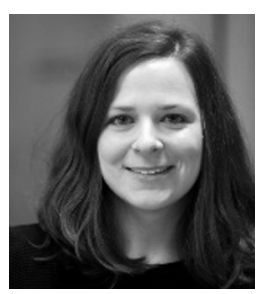

Alzbeta Bártová attained her PhD in Social Policy from the University of Edinburgh in 2017. Since 2020, she is an MSCA Fellow at the Centre for Sociological Research at KU Leuven. Her research focuses on child-related leave policies in Europe and their impact on social and gender inequality, and sociodemographic outcomes.

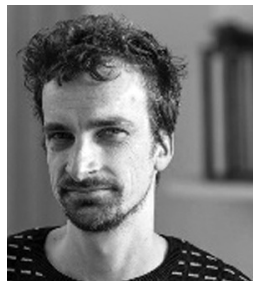

Wim Van Lancker is an Assistant Professor of social work and social policy, affiliated to the Centre for Sociological Research, KU Leuven. His research focuses on the link between the design of family and social policies and their outcomes in terms of poverty, inequality, employment and well-being. 